\title{
Manifestaciones clínicas y respuesta leucocitaria producidas por la vacunación antisarampión
}

\author{
Dr. Marcial Osorio F.; Dr. Maruel Olivares G.; T'M. Patricia Chadud M.; \\ Dra. Liana Schksinger F.; T.M. Marianela Arćralo N.; Dr. Abraham Stekel G.1 * \\ Clinical and leukocyte response after measles vaccination
}

\begin{abstract}
Clinical and white cell counts response were evalu ted in forty eight month old, well nourished infants, after the administration of an attenuated measles yaccine of the Schwarz strain: fever was reported in $66.7 \%$ of them (temperatuse $>38^{\circ} \mathrm{C}$ ), ather symptoms were coryza $(66.7 \%)$, cough $(52.1 \%$, diarrhea $(43.8 \%)$, rash $(14.6 \%)$. Measles vaccine administration induced a drop in total leukocyte counts with increased absolute numbers of band cells.

(Key words: Measles vaccine, infants, leucocyte, clinical trial).
\end{abstract}

El desarrollo de vacunas vjvas atenuadas ant 1 sarampión comenzó en el affo 1954, entregándo. se a firies de la misma década la vacuna Edmonston $B$ para uso clínico. La vacuna, de alta capacidad inmunológica producía con gran fre. cuencid reacciones adversas como fiebre $y$ exantema que dificultaron su uso masivo, to que llevó a desarrollar vacunas con virus más atenuados que produjeran menos manifestaciones clínicas y buena respuesta inmune. En nuestro pais, donde existe un programa de vacunación con amplia cobertura, no hemos encontrado in. formación acerca de los efectos colaterales de la vacuna Schwarz administrada a los 12 meeses de vida en dosis completa.

El objetivo de este trabajo fue evaluar, en lactantes de 12 meses, las modificaciones producidas por una vacuna con virus vivo atenuado antisarampión. de la cepa Schwarz.

\section{MATERIAL Y METODO}

Cor el consentimiento de los padres, se seleccionaron 48 lactantes sanos, eutróficos, de 12 meses de edad, sin antecedentes de sarampión ni enfermedades febriles en los 15 dias anteriores. Ll día 0 , se procedió a la inmunización con una cepa Schwarz en dosis completa. Un mético pediatra realizó la selección de los niños e instruyó a las madres para controlar y registrar, entre los días 7 y 14, la aparición del exantema, coriza, tos; el numero de deposiciones y la temperatura rectal En los días 7,9 y 11 del seguimiento se realizaron controles médicos te los niños y confirmó la ínformación reco-

1. Unidades de Hematología e Inmunología, Instituto de Nutrición y Tecnología de los Alimentos, Universidad de Chile.

* Trabajo financiado parcialmente por CONICYT y Nestlé Nutrition Researcl Grant Programme. lectada por las madres. Cuarenta y seis lactantes de edad similar, que no recibieron vacuna, sirvieson como grupo control en la evaluación de los síntomas.

Tn los días 0,9 y 30 , se obtuyo de cada paciente una muestra de sangre venosa cn ayunas para contar lcucocitos (Coulter Counter Modelo ZBI, Hialeah, F1) y fórmula diferencial. En el análisis estadístico se usaron has prucbas de Student pareada, de Chi cuadrado y de Fisher.

\section{RESULTADOS}

Manifestaciones clínicas:

Los lactantes vacunados tuvieron, en orden decreciente de frecuencia, fiebre, coriza, tos, diarrea y exantema (Tabla 1). La frecuencia de fiebre, coriza y exantema fue significativamente mayor en los niños vacunados que en los controles. En cambio no existieron diferencias en la frecuencia de tos y diarrea en ambos grupos. $\mathrm{La}$ fiebre $y$ el exantema fueron los signos de aparición más tardios y su duración fue similar (Tabla 2).

La distribución de la frecuencia relativa de la temperatura máxima se muestra en la Tabla 3.

E] recuento de leucocitos experimentó una disminución significativa 9 días después de la inyección de la vacuna $(\mathrm{P}<0,005)$, lo mismo ocurrió con los eosinófilos $(p<0,001)$ y linfocitos $(p<0,001)$, al mismo tiempo hubo aumento, igualmente significativo, del número absoluto de baciliformes $(p<0,001)$ (Figs. l y 2 ). Estas modificaciones desaparecieron el día 30 , persistiendo sólo un descenso significativo del recuento de eosinófilos $(p<0,01)$. No se observaron variacio. nes en el número absoluto de basófilos, segmentados, monocitos y linfocitos hiperbasófilos.

No se encontró correlación entre las manifes- 


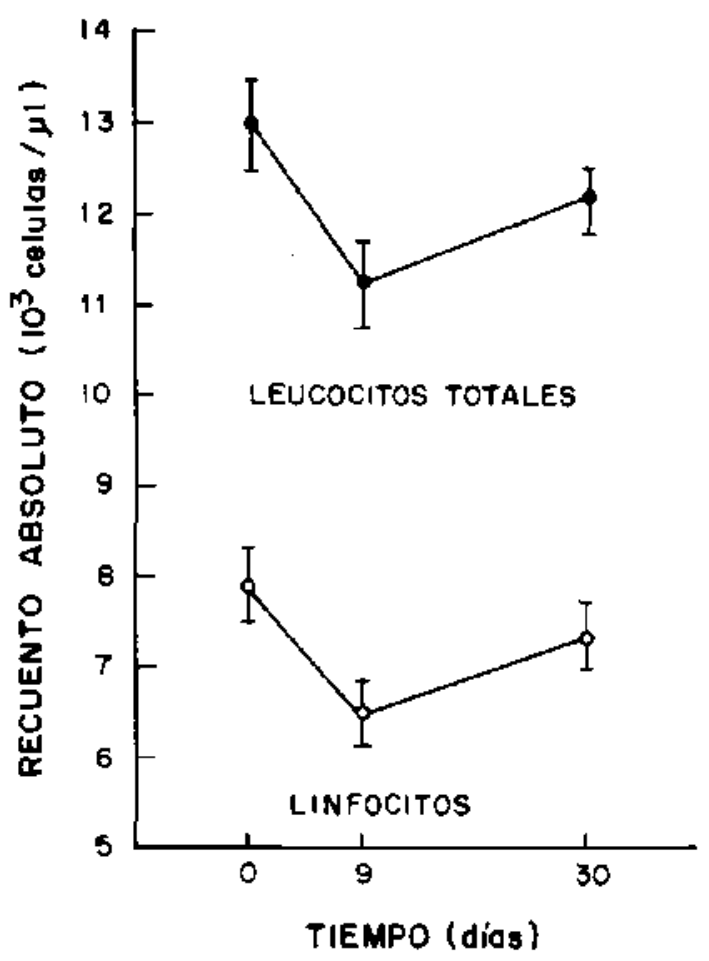

Figura 1. Evolución de los leucocitos totales y número absoluto de linfocitos en lactantes que recibieron vacunación antisarampión. (promedio y error estándar de la media).

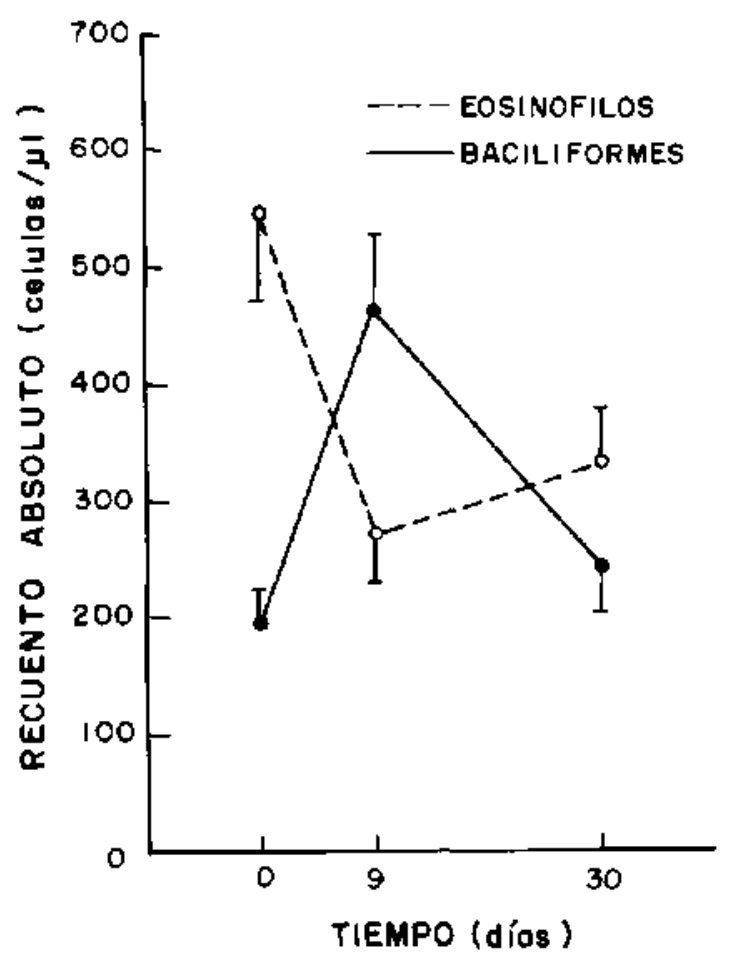

Figura 2. Evolución del recuento absoluto de eosinófilos y bacilifotmes en lactantes que recibieron vacunación antisarampión. (promedio y error de estándar de la media .

Tabla 1.

Manifestaciones clínicas cn lactantes que recibieron vacunación antisarampión

\begin{tabular}{lcccccc}
\hline & $\mathrm{N}$ & $\begin{array}{c}\mathrm{T} 0>38^{\circ} \mathrm{C} \\
\%\end{array}$ & $\begin{array}{c}\text { Coriza } \\
\%\end{array}$ & $\begin{array}{c}\text { Tos } \\
\%\end{array}$ & $\begin{array}{c}\text { Diarrea } \\
\%\end{array}$ & $\begin{array}{c}\text { Exantema } \\
\%\end{array}$ \\
\hline Vacunados & 48 & 66,7 & 66,7 & 52,1 & 43,8 & 14,6 \\
No vacunados & 46 & 15,2 & 41,3 & 37,0 & 23,9 & 2,2 \\
\hline $\mathrm{p}>$ & 0,001 & 0,03 & $\mathrm{NS}$ & $\mathrm{NS}$ & 0,04
\end{tabular}

Tabla 2.

Día de iniciación y duración de manifestaciones clínicas en lactantes que recibieron vacuna antisarampión*

\begin{tabular}{lccccc}
\hline & $T^{\mathbf{0}}>38^{\circ} \mathrm{C}$ & $\begin{array}{c}\text { Coriza } \\
\%\end{array}$ & $\begin{array}{c}\text { Tos } \\
\%\end{array}$ & $\begin{array}{c}\text { Diarrea } \\
\%\end{array}$ & $\begin{array}{c}\text { Exantema } \\
\%\end{array}$ \\
\hline Aparición & $7,8 \pm 1,7$ & $4,5 \pm 2,8$ & $5,7 \pm 2,5$ & $5,9 \pm 2,8$ & $8,8 \pm 2,2$ \\
Duración & $2,5 \pm 1,5$ & $6,1 \pm 3,2$ & $5,2 \pm 2,3$ & $2,2 \pm 1,3$ & $2,6 \pm 1,0$ \\
\hline
\end{tabular}

* Promedio de días y desviación estándar. 
taciones clínicas, alza térmica, recuento y fórmula leucocitaria.

\section{DISCUSION}

Este estudio muestra que la vacuna Schwarz produce manifestaciones clíricas, como alza febril, coriza y exantema en un porcentaje no despreciable de los lactantes inmunizados. Estas manifestaciones son de leve o moderada intensidad, no comprometiendo más allá la salud de los niños.

Estudios similares reportados desde 1962, con distintos tipos de vacunas vivas atenuadas, han mostrado resultados comparables (Tabla 4). Sin embargo las frecuencias de fiebre y diarrea fueron mayores è nuestros pacientes que las descritas por Schwarz en Israel utilizando la misma vacuna ${ }^{3}$. El mayor porcentaje de diarrea podría explicarse por diferencias de definición de este trastorno, puesto que, tanto en nuestro estudio como en el antes citado; no se encontraron diferencias significativas en la frecuencia de diarrea al comparar los niños vacunados con los controles. Desconocemos cuál sería la explica. ción de las variaciones en la incidencia de coriza y fiebre, en todo caso nuestro criterio para detinir fiebre $\left(\geqslant 38^{\circ} \mathrm{C}\right)$ fue algo más exigente que el elegido por Schwarz $\left(<38,3^{\circ} \mathrm{C}\right)$ : en apro- ximadamente $60 \%$ de nuestros casos al alza térmica fue inferior o igual a $38,5 \circ \mathrm{C}$. Cabe señalat la importancia de contar con un grupo de control en este tipo de investigaciones, ya que muchas de las manifestaciones atribuíbles a la vacuna son inespecificas y de alta prevalencia entre los niños.

Las modificaciones de la serie blanca son similares a las descritas por Black y col.5 con la vacuna Edmonston, difiriendo sólo en que este autor encontró una disminución importante en e] número absoluto de neutrófilos entre los dias 8 y 15 post inmunización. No se sabe si las alteraciones de la serie blanca son bebidas a disminución de la producción, aumento de la destrucción, o cambios en la distribución de los leucocitos.

Es por lo tanto posible observar alteraciones clínicas y variaciones hematológicas en los lactan tes inmunizados con virus de sarampión atenuado.

\section{RESUMEN}

Se analizan las manifestaciones clínicas y respuesta leucocitaria a una vacuna antisacampión con virus atenuado de la cepa Schwarz en 48 lactantes eutróficos de 12 meses. Un $66,7 \%$ de los sujetos presentó temperatura superior a $38^{\circ} \mathrm{C}$,

Tabla 3.

Distribución de frecuencia de temperatura en lactantes que recibieton vacunación antisarampión

\begin{tabular}{cccccc}
\hline Temperatura $\left({ }^{\circ} \mathrm{C}\right)$ & $\$ 37,5$ & $37,6-38,0$ & $38,1-38,5$ & $38,6-39,0$ & $\leqslant 39,0$ \\
$\mathrm{~N}^{\mathrm{No}}$ casos & 8 & 8 & 13 & 11 & 8 \\
\hline$\%$ & 16,7 & 16,7 & 27,0 & 22,9 & 16,7
\end{tabular}

Tabla 4

Comparación de incidencia de manifestaciones clínicas en nī̄os que recibieron distintas vacunas antisarampión *

\begin{tabular}{lccccccc}
\hline $\begin{array}{l}\text { Tipo } \\
\text { Vacunas }\end{array}$ & $\begin{array}{c}\text { No }^{\circ} \\
\text { Vactunados }\end{array}$ & $\begin{array}{c}\text { Fiebre } \\
(\%)\end{array}$ & $\begin{array}{c}\text { Coriza } \\
(\%)\end{array}$ & $\begin{array}{c}\text { tos } \\
(\%)\end{array}$ & $\begin{array}{c}\text { Diarrea } \\
(\%)\end{array}$ & $\begin{array}{c}\text { Exanterna } \\
(\%)\end{array}$ & Referencia \\
\hline Edmonston & 120 & 50 & 3 & & 12 & 19 & Katz y Col. $^{2}$ \\
Edmonston & 88 & 35 & 18 & 9 & 0 & 25 & Schwarz y Col. \\
Moraten & 84 & 12 & $\mathrm{I}$ & 2 & 2 & 8 & Schwarz y Col. $^{3}$ \\
Schwarz & 81 & 16 & 6 & 16 & 0,4 & 17 & Schwarz y Col. $^{3}$ \\
Moraten & 196 & 19 & 0 & 0 & 0 & 9 & Ristori y Coi. $^{4}$ \\
Schwarz & 48 & 52 & 25 & 15 & 20 & 12 & Osorio y Col.
\end{tabular}

* El porcentaje de síntomas se expresó como:

frecuencia sintomas en vacunados-frecuencia en no vacunados. 


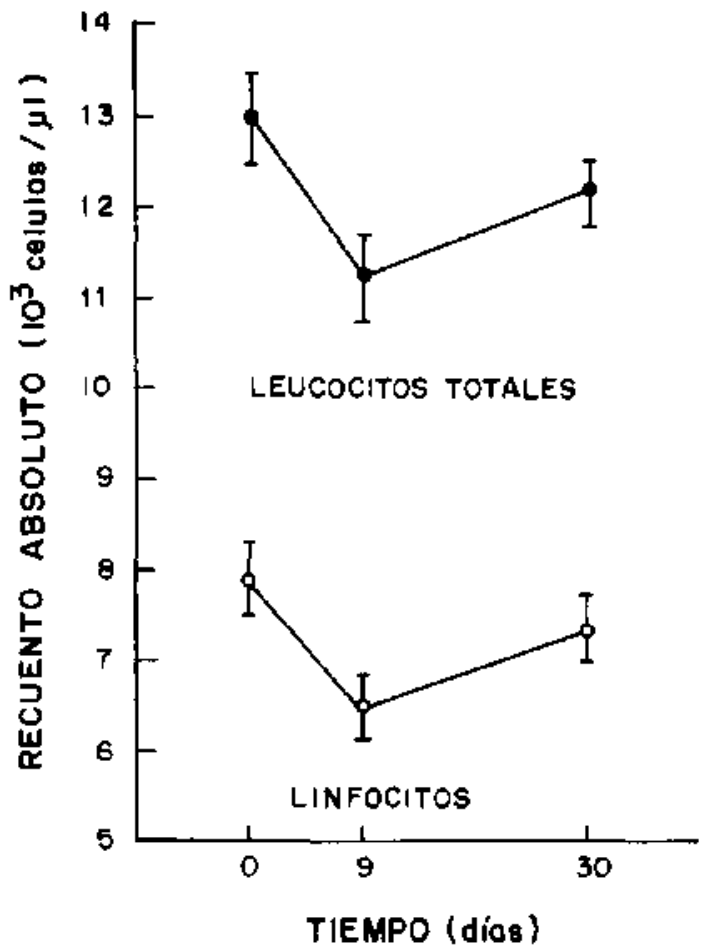

Figura 1. Evolución de los leucocitos totales y número absoluto de linfocitos en lactantes que recibieron vacunación antisarampión. (promeđio y error estándar de la medir).

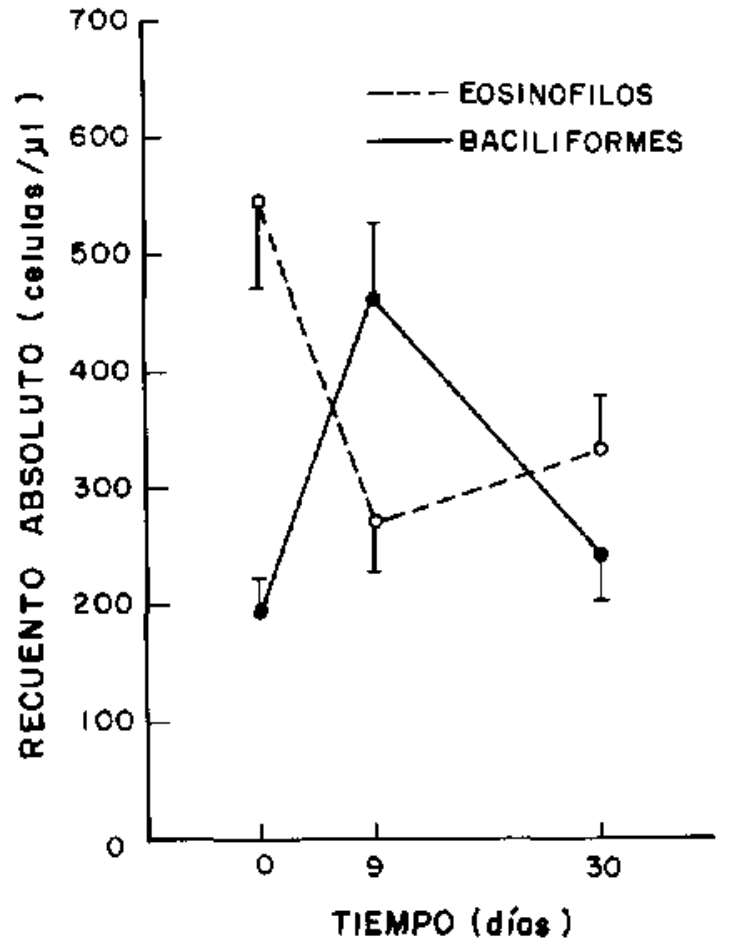

Figura 2. Evolución del recuento absoluto de eosinófilos $y$ baciliformes en lactantes que recibier on vacunación antisarampión. (promedio y cror de estándar de la media).

Tabla 1.

Manifestaciones clínicas en lactantes que recibieron vacunación antisarampión

\begin{tabular}{lcccccc}
\hline & $\mathrm{N}$ & $\begin{array}{c}\mathrm{T}>380 \mathrm{C} \\
\%\end{array}$ & $\begin{array}{c}\text { Coriza } \\
\%\end{array}$ & $\begin{array}{c}\text { Tos } \\
\%\end{array}$ & $\begin{array}{c}\text { Diarrea } \\
\%\end{array}$ & $\begin{array}{c}\text { Exantema } \\
\%\end{array}$ \\
\hline Vacunados & 48 & 66,7 & 66,7 & 52,1 & 43,8 & 14,6 \\
No vacunados & 46 & 15,2 & 41,3 & 37,0 & 23,9 & 2,2 \\
\hline $\mathrm{p}>$ & & 0,001 & 0,03 & NS & NS & 0,04
\end{tabular}

Tabla 2.

Dfa de iniciación y duración de manifestaciones clínicas en lactantes que recibieron vacuna antisarampión*

\begin{tabular}{lccccc}
\hline & $T^{0}>38^{\circ} \mathrm{C}$ & $\begin{array}{c}\text { Coriza } \\
\%\end{array}$ & $\begin{array}{c}\text { Tos } \\
\%\end{array}$ & $\begin{array}{c}\text { Diarrea } \\
\%\end{array}$ & $\begin{array}{c}\text { Exantema } \\
\%\end{array}$ \\
\hline Aparición & $7,8 \pm 1,7$ & $4,5 \pm 2,8$ & $5,7 \pm 2,5$ & $5,9 \pm 2,8$ & $8,8 \pm 2,2$ \\
Duración & $2,5 \pm 1,5$ & $6,1 \pm 3,2$ & $5,2 \pm 2,3$ & $2,2 \pm 1,3$ & $2,6 \pm 1,0$ \\
\hline
\end{tabular}

* Promedio de días y desviación estándar. 
taciones clínicas, alza térmica, recuento y fórmu. la leucocitaria.

\section{DISCUSION}

Este estudio muestra que la vacuna Schwarz produce manifestaciones clínicas, como alza febril, coriza y exantema en un porcentaje no despreciable de los lactantes inmunizados. Estas manifestaciones son de leve o moderada intensidad, no comprometiendo más allá la salud de los niños.

Estudios similares reportados desde 1962, con distintos tipos de vacunas vivas atenuadas, han mostrado resultados comparables (Tabla 4). Sin embargo las frecuencias de fiebre y diarrea fueron mayores en nuestros pacientes que las descritas por Schwarz en Israel utilizando la misma vacuna $^{3}$. El mayor porcentaje de diarrea podria explicarse por diferencias de definición de este trastorno, puesto que, tanto en nuestro estudio como en el antes citado; no se encontraron diferencias significativas en la frecuencia de diarrea al comparar los niños vacunados con los controles. Desconocemos cuál sería la explicación de las variaciones en la incidencia de coriza y fiebre, en todo caso nuestro criterio para definir fiebre ( $\geqslant 38^{\circ} \mathrm{C}$ ) fue algo más exigente que el elegido por Schwarz $\left(<38,3^{\circ} \mathrm{C}\right)$ : en apro- ximadamente $60 \%$ de nuestros casos al alza térmica fue inferior o igual a $38,5 \circ \mathrm{C}$. Cabe señalar la importancia de contar con un grupo de control en este tipo de investigaciones, ya que muchas de las manifestaciones atribuibles a la vacuna son inespecíficas $y$ de alta prevalencia entre los niños.

Las modificaciones de la serie blanca son similares a las descritas por Black y col.5 con la vacuna Edmonston, difiriendo sólo en que este autor encontró una disminución importante en el número absoluto de neutrófilos entre los días $8 \mathrm{y}$ 15 post inmunización. No se sabe si las altera. ciones de la serie blanca son bebidas a disminución de la producción, aumento de la destrucción, o cambios en la distribución de los leucocitos.

Es por lo tanto posible observar alteraciones clínicas y variaciones hematológicas en los lactantes inmunizados con virus de sarampión atenuado.

\section{RESUMEN}

Se analizan las manifestaciones clinicas y respuesta leucocitaria a una vacuna antisarampión con virus atenuado de la cepa Schwarz en 48 lactantes eutróficos de 12 meses. Un $66,7 \%$ de Jos sujetos presentó temperatura superior a $38^{\circ} \mathrm{C}$,

Tabla 3.

Distribución đe frecuencia de temperatura en lactantes que recibieron vacunación antisarampión

\begin{tabular}{cccccc}
\hline Temperatura $\left({ }^{\circ} \mathrm{C}\right)$ & $\leqslant 37,5$ & $37,6-38,0$ & $38,1-38,5$ & $38,6-39,0$ & $\leqslant 39,0$ \\
$\mathrm{No}^{\circ}$ casos & 8 & 8 & 13 & 11 & 8 \\
\hline$\%$ & 16,7 & 16,7 & 27,0 & 22,9 & 16,7
\end{tabular}

Tabla 4

Comparación de incidencia de manifestaciones clínicas en niños que recibier on distintas vacunas antisarampión *

\begin{tabular}{|c|c|c|c|c|c|c|c|}
\hline $\begin{array}{l}\text { Tipo } \\
\text { Vacunas }\end{array}$ & $\begin{array}{c}\text { No }^{\circ} \\
\text { Vacunados }\end{array}$ & $\begin{array}{l}\text { Fiebre } \\
(\%)\end{array}$ & $\begin{array}{c}\text { Coriza } \\
(\%)\end{array}$ & tos & $\begin{array}{c}\text { Diarreat } \\
(\%)\end{array}$ & $\begin{array}{c}\text { Fxantema } \\
(\%)\end{array}$ & Referencia \\
\hline Edmonston & 120 & 50 & 3 & & 12 & 19 & Katz y Col. ${ }^{2}$ \\
\hline Edmonston & 88 & 35 & 18 & 9 & 0 & 25 & Schwarz y Col ${ }^{3}$ \\
\hline Moraten & 84 & 12 & 1 & 2 & 2 & 8 & Schwarz y Col. ${ }^{3}$ \\
\hline Schwarz & 81 & 16 & 6 & 16 & 0,4 & 17 & Schwarz y $\mathrm{Col}^{3}$ \\
\hline Moraten & 196 & 19 & 0 & 0 & 0 & 9 & Ristori y Col. ${ }^{4}$ \\
\hline Schwarz & 48 & 52 & 25 & 15 & 20 & 12 & Osorio y Col. \\
\hline
\end{tabular}

* El porcentaje de síntomas se expresó como:

frecuencia síntomas en vacunados-frecuencia en no vacunados. 
coriza $(66,7 \%)$, tos $(52,1 \%)$, diarrea $(43,8 \%)$, exantema $(14,6 \%)$. La respuesta leucocitaria se caracterizó por una caída en el recuento de linfocitos y del número absoluto de eosinófilos. con un aumento del número absoluto de baciliformes.

\section{REFERENCIAS}

1. Giders, J.F.. Peebtes, T.C.: Propagation in tissue cult ure of eytopathogenic agents from patients with measles. Proc Soc Fxp Biol Med 86: 277, 1954.
2. Katz, S.L., Moriey. D.C., Kruymon, S.: Attennated measles vaccine in nigerian children. Am J Dis Child 103: 232, 1962.

3. Schwarz, T., Klingberg, W., Nishni, M., Goldblum, N. Gerichter, C. Cockburn, W.C.: A comparative study of four live ineasles vaccines in Israel. Bul Who 39: 285,1968 .

4. Ristori, C. Bocicardo, H., Borgono, J.M., Greiber, R., Heras, E., Carililo, B., Solari, $G$, Concha, $F$. Estu dios clínicos $y$ serológicos con vacuna antisar ampión viva mas atenuada (Moraten) en Chile. Rev Med Chil 98: 42, 1970 .

5. Black, F.I... Sheridan, S.R.: Blood leukocyte response to live measles vaccinc. Am J Dis Child IL3: $301,1967$. 